\title{
Research on the cooperative work of multi manipulator in hot stamping production line
}

\author{
Gang Zheng, Liang Wang, Qiang Wang, Yi Sun, Ju Meng, and Yisheng \\ Zhang*
}

\author{
State Key Laboratory of Material Processing and Die \& Mould Technology \\ Huazhong University of Science and Technology, Wuhan 430074, P.R. China \\ *Corresponding author: zhangys@mail.hust.edu.cn
}

Keywords: hot-stamping; multi manipulator; synergic movement; sheet handover

Abstract. In hot-stamping production line of high-strength steel, when high-temperature sheet gets out of furnace, it needs to be delivered as soon as possible to press for stamping, to reduce high temperature oxidation and plasticity reduction caused by temperature drop, and improve the efficiency of the production line. There is a good solution to it, making the furnace unloading robot and the press feeding robot do synergic movement, and completing sheet handover during it. This paper, based on experiment of two axes synergic movement, analyses the feasibility and significance that realizing sheet handover during synergic movement of multi manipulator.

\section{Introduction}

With the need of development of lightweight automobile, high strength steel sheet hot-stamping technology is rapidly developing [1,2]. Hot-stamping process can be briefly summarized as follows: send cold steel sheet into heating furnace, heat it to $850 \sim 950 \square$ in the heating furnace to austenitize it, then send it to press for stamping and quenching to get high-strength sheet [3]. The transportation time from furnace to press should be as shorter as possible, because heat sheets are easily oxidized in air, and sheet temperature will reduce during conveying, which will cause plasticity reduction and affect the molding quality $[4,5]$. In addition, reduced transportation time can also boost productivity.

In common hot-stamping production lines, furnace unloading robot and press feeding robot are at rest during sheet handover. That means, sheet will go through the process of accelerated and decelerated twice during the transportation, and the cylinder drive the gripper to accomplish sheet handover will also take some time. But if we can let the furnace unloading robot and press feeding robot do cooperative work, making them do synergic movement and accomplish sheet handover during movement, we can not only reduce the time that furnace unloading robot decelerating to zero and press feeding robot accelerating from zero, but also save the time of sheet handover. Thus, it can significantly reduce the total transport time. The difference can be clearly seen from figure 1 .

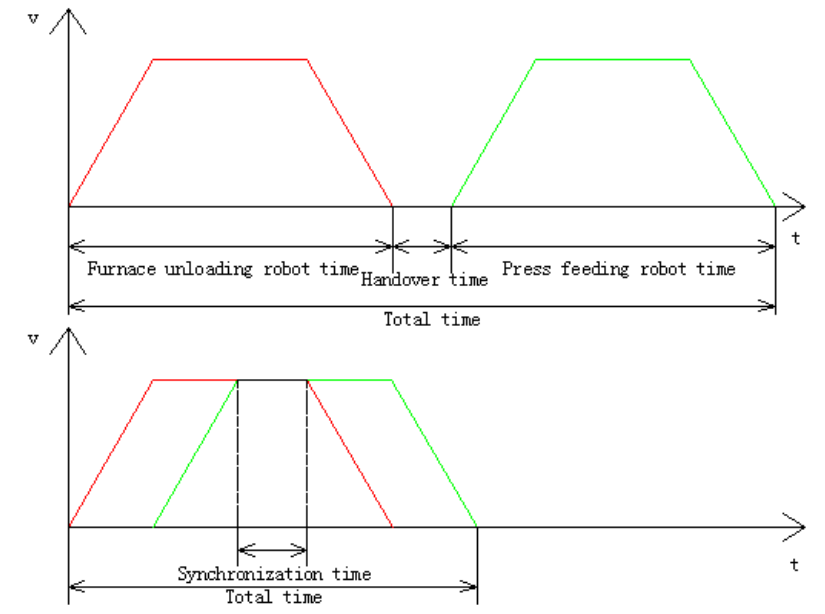

Fig.1. the difference between do and not do cooperative work

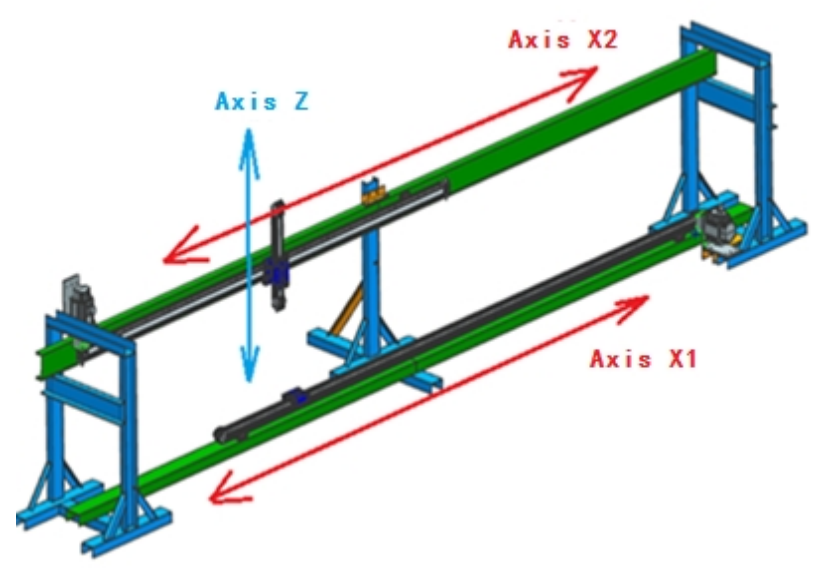

Fig.2. mechanism of experiment 
The paper, using two-axis linear motion mechanism to simulate the actual transportation process of sheet from furnace unloading robot to press feeding robot in hot-stamping production line, analysis the feasibility of realizing sheet handover during synergic movement, and explore how much time it can save

\section{Experiment introduction}

\section{Equipment structure}

In order to be as close to the actual situation on the production line, we designed two-axis linear motion mechanism, besides there is also a vertical axis, which is designed to transfer sheet. The mechanism is as figure 2 .

\section{Mechanical parameter}

As figure 2, the motor drive the slider on the linear slide rail to move through the belt wheel. Axis $\mathrm{X} 1$ represents the movement of furnace unloading robot; axis X2 represents the movement of press feeding robot; axis $\mathrm{Z}$ represents the vertical movement of sheet handover. Axis X1's effective travel is $3780 \mathrm{~mm}$, Axis X2's effective travel is $2820 \mathrm{~mm}$, the leads of their belt wheel are $95 \mathrm{~mm}$, the overlap distance of X1 and X2 is $1520 \mathrm{~mm}$. Axis Z's effective travel is $220 \mathrm{~mm}$, the lead of its belt wheel is $75 \mathrm{~mm}$, due to the short travel and slow speed, motor of axis $Z$ requires a speed reducer. We choose a speed reducer whose gear ratio 20:1.

\section{Control system}

In order to achieve multi-axis motion control, in particular synergic movement 0 X X1 and X2, we choose multi-axis motion controllers and servo drive systems. The controller is Estun ESMOTION-NGEV-211B1, with function of both logic and motion control; it can achieve a maximum of 6-axis interpolation, and have 16 digital inputs and 14 digital outputs. The drive of X1 and $\mathrm{X} 2$ are Estun PRONET-15AMA, whose corresponding motors are EMG-15ASA22; the motor' rated torque is $7.16 \mathrm{~N} \mathrm{~m}$, and its rated speed is $2000 \mathrm{r} / \mathrm{min}$. The drive of $Z$ is Estun PRONET-02AMA, whose corresponding motor is EMG-02ASA24; the motor' rated torque is $0.64 \mathrm{~N} \mathrm{~m}$, and its rated speed is 3000r/min.

\section{Scheme analysis}

The key purpose of the experiment, firstly, is to verify the feasibility; secondly, is to adjust the parameters to reduce the transportation time as much as possible.

\section{Feasibility analysis}

Axis Z's movement takes time, and the cylinder drive the clutch to accomplish sheet handover also takes some time. Only X1 and X2 have long enough synchronization time in the cooperative movement, that sheet handover process can be achieved. Synchronization time is mainly affected by the overlap distance, speed, acceleration and deceleration. Synchronization time is not the longer the better, it is just need be enough to accomplish the process of sheet handover. Based on the experience of actual production line, the minimum time of sheet handover is about $0.8 \mathrm{~s}$.

The motion control system as is actually a half-closed-loop feedback control system, X1 and X2 are moving fast when doing sheet handover. Motor's position control has error, motor's position to slider's position from mechanism has error, and it results the position error. Although the gripper allows some position error when designed, but if the error is too great, the process of sheet handover is impossible to accomplish. The gripper's allowing error designed is $10 \mathrm{~mm}$.

\section{Movement analysis}

Shorten the time of transportation is the ultimate goal of the experiment. In order to simplify the process of movement, we consider that X1 and X2's velocity-time curve is T-speed curve, acceleration is constant acceleration, and deceleration is constant deceleration.

Because of the overlap distance limited, X1 and X2 is not actually synchronization at the highest speed, but at a low speed. So there will be plenty of time for synchronization, the low speed synchronization movement process is shown in Figure 3. 


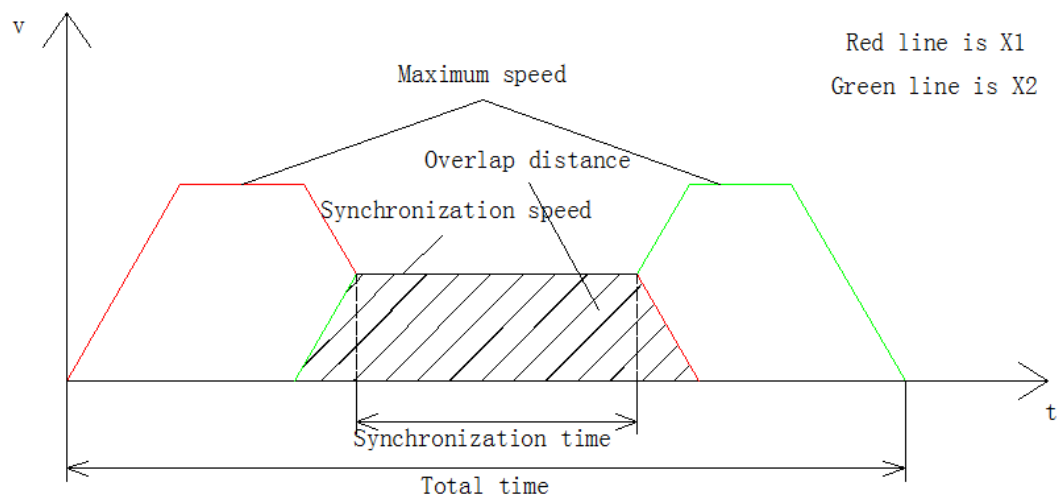

Fig.3. low speed synchronization movement process

$\mathrm{X} 1$ accelerates to maximum speed and then slow down to the synchronization speed, $\mathrm{X} 2$ accelerates to synchronous speed and then accelerates to maximum speed. Total time of movement includes X1's movement time before it reaches the synchronized segment and X2's movement time after it leaves the synchronized segment, and synchronization time.

The sum of X2's first acceleration distance, X1's last deceleration distance and synchronization distance must be less than the overlap distance. Synchronization distance equals to the product of synchronization speed and synchronization time.

Acceleration affects acceleration time and acceleration distance, deceleration affects deceleration time and deceleration distance. The greater acceleration and deceleration are, the less they time are, the shorter their distance are. So acceleration and deceleration are the greater the better. But, they are limited by factors like motor's performance, load magnitude, mechanical stiffness and so on. In the experiment the motor's acceleration and deceleration are set to $100000 \mathrm{rpm} / \mathrm{s}$.

In the experiment, the maximum speed of $\mathrm{X} 1$ and $\mathrm{X} 2$ are set to $3 \mathrm{~m} / \mathrm{s}$ (equal to motor's $1894.74 \mathrm{rpm})$, the overlap distance is $1520 \mathrm{~mm}$. Thus, the key problem of the experiment is to find a suitable synchronization speed to make the synchronization time approximate $0.8 \mathrm{~s}$.

\section{Experiment results}

In the experiment it can be found that, by adjusting parameters, the position error of X1 and X2 can be controlled into $10 \mathrm{~mm}$ when they are in the synchronized segment, which is allowed by the gripper. When the sliders' maximum speed are $3 \mathrm{~m} / \mathrm{s}$, motors' acceleration and deceleration are $100000 \mathrm{rpm} / \mathrm{s}$ and the overlap distance is $1520 \mathrm{~mm}$, we used cooperative work and set the synchronization speed to $1 \mathrm{~m} / \mathrm{s}$, we got $1.43 \mathrm{~s}$ synchronization time and $3.13 \mathrm{~s}$ total time. The synchronization is greater than $0.8 \mathrm{~s}$, so sheet handover can be accomplished.

Keep the maximum speed, acceleration and deceleration unchanged, we did not use cooperative work, we got the total transportation time of $3.23 \mathrm{~s}$, which was greater than $3.13 \mathrm{~s}$. That means using cooperative work can save time.Using cooperative work, and keeping maximum speed, acceleration, deceleration and overlap distance unchanged, we got synchronization time and total time in different synchronization speed, as table1 shows.Obviously, with the increasing of synchronization speed, the synchronization time and total time are reduced. When the Synchronization speed is $1.6 \mathrm{~m} / \mathrm{s}$, the synchronization time is $0.81 \mathrm{~s}$, the total time is $2.54 \mathrm{~s}$, and cooperative work saves $0.69 \mathrm{~s}$. But, if Synchronization speed is too small, like $0.5 \mathrm{~m} / \mathrm{s}$, it can be found that cooperative work takes more time on the contrary.

In hot-stamping production line, the overlap distance may not reach $1520 \mathrm{~mm}$. Using cooperative work, and keeping maximum speed, acceleration, deceleration and unchanged, according the regulation above, we can find a suitable synchronization speed to make synchronization time approximate $0.8 \mathrm{~s}$ under different overlap distance, as table 2 shows. It can be seen that the longer the overlap distance is, the greater the synchronization speed can be, and the shorter the total time is, and the more time it can save. 
Table1. Synchronization time and total time in different synchronization speed

\begin{tabular}{cccc}
\hline $\begin{array}{c}\text { Synchronizatio } \\
\mathrm{n} \mathrm{speed}(\mathrm{m} / \mathrm{s})\end{array}$ & $\begin{array}{c}\text { Synchronizatio } \\
\mathrm{n} \text { time}(\mathrm{s})\end{array}$ & Total time(s) & $\begin{array}{c}\text { Saving } \\
\text { time(s) }\end{array}$ \\
\hline 0.5 & 2.97 & 4.68 & -1.45 \\
1 & 1.43 & 3.13 & 0.10 \\
1.4 & 0.95 & 2.68 & 0.55 \\
1.5 & 0.87 & 2.60 & 0.63 \\
1.6 & 0.81 & 2.54 & 0.69 \\
1.7 & 0.75 & 2.48 & 0.75 \\
1.8 & 0.69 & 2.42 & 0.81 \\
2.5 & 0.41 & 2.16 & 1.07 \\
3 & 0.27 & 2.04 & 1.19 \\
\hline
\end{tabular}

Table2. Suitable solution under different overlap distance

\begin{tabular}{ccccc}
\hline $\begin{array}{c}\text { Overlap } \\
\text { distance }(\mathrm{mm})\end{array}$ & $\begin{array}{c}\text { Synchronization } \\
\text { speed }(\mathrm{m} / \mathrm{s})\end{array}$ & $\begin{array}{c}\text { Synchronization } \\
\text { time }(\mathrm{s})\end{array}$ & $\begin{array}{c}\text { Total } \\
\text { time }(\mathrm{s})\end{array}$ & $\begin{array}{c}\text { Saving } \\
\text { time }(\mathrm{s})\end{array}$ \\
\hline 300 & 0.35 & 0.81 & 2.99 & 0.24 \\
700 & 0.79 & 0.79 & 2.86 & 0.37 \\
1000 & 1.10 & 0.79 & 2.71 & 0.52 \\
1300 & 1.41 & 0.79 & 2.59 & 0.64 \\
\hline
\end{tabular}

\section{Summary}

To sum up, the experiment proves that sheet handover during synergic movement of multi manipulator is feasible, and it can reduce a lot of time compared with the way without cooperative work. The longer the overlap distance is, the more time we can save.

\section{Acknowledgements}

This research work is financially supported by the National Natural Science Foundation of China (Grant No. 51275185 and No.51405171).

\section{References}

[1] Karbasian H, Tekkaya A E. A review on hot stamping, Journal of Materials Processing Technology, 210(2010)2103-2118.

[2] Mori K, Saito S, Maki S. Warm and hot punching of ultrahigh strength steel sheet, CIRP Annals-Manufacturing Technology, 57(2008)321-324.

[3] Lechler J, Merklein M. Hot stamping of ultrahigh strength steels as a key technology for lightweight construction, materials Science and Technology (MS\&T), Pittsburgh, Pennsylvania, 2008.

[4] Merklein M, Lechler J. Investigation of the thermo-mechanical properties of hot stamping steels, Joumal of Materials Processing Technology, 177(2006)452-455.

[5] Abbasi M, Saeed-Akbari A, Naderi M. The effect of strain rate and deformation temperature on the characteristics of isothermally hot compressed boron-alloyed steel, Materials Science and Engineering, 538(2012)356-363. 